\title{
Imidazolium-based ionic liquid type dependence of the bending response of polymer actuators
}

\author{
R. Mejri ${ }^{1,2}$, J. C. Dias ${ }^{2,3}$, S. Besbes Hentati ${ }^{1}$, G. Botelho ${ }^{3}$, J.M.S.S. Esperança ${ }^{4,5}$, \\ C. M. Costa ${ }^{2,3, *}$, S. Lanceros-Mendez $z^{2,6,7, *}$
}

${ }^{1}$ Department of Chemical, University of Carthage, Faculty of Sciences of Bizerte, 7021 Zarzouna, Bizerte, Tunisia

${ }^{2}$ Departamento/Centro de Física, Universidade do Minho, Campus de Gualtar, 4710-057 Braga, Portugal.

${ }^{3}$ Departamento/Centro de Química, Universidade do Minho, Campus de Gualtar, 4710057 Braga, Portugal.

${ }^{4}$ Instituto de Tecnologia Química e Biológica António Xavier, Universidade Nova de Lisboa, Av. da República, 2780-157, Oeiras, Portugal

${ }^{5}$ LAQV, REQUIMTE, Departamento de Química, Faculdade de Ciências e Tecnologia, Universidade Nova de Lisboa, 2829-516 Caparica, Portugal

${ }^{6}$ BCMaterials, Parque Científico y Tecnológico de Bizkaia, 48160-Derio, Spain

${ }^{7}$ IKERBASQUE, Basque Foundation for Science, 48013-Bilbao, Spain

*corresponding $\quad$ authors: $\quad$ cmscosta@fisica.uminho.pt;

$\underline{\text { senentxu.lanceros@bcmaterials.net }}$

\begin{abstract}
Actuators based on polymer blends of poly(vinylidene fluoride) (PVDF) with $40 \%$ of different ionic liquids (IL) are prepared by solvent casting. $\left[\mathrm{C}_{2} \mathrm{mim}\right][\mathrm{Cl}],\left[\mathrm{C}_{6} \mathrm{mim}\right][\mathrm{Cl}]$, $\left[\mathrm{C}_{10 \mathrm{mim}}\right][\mathrm{Cl}],\left[\mathrm{C}_{2} \mathrm{mim}\right]\left[\mathrm{NTf}_{2}\right],\left[\mathrm{C}_{6} \mathrm{mim}\right]\left[\mathrm{NTf}_{2}\right]$ and $\left[\mathrm{C}_{10 \mathrm{mim}}\right]\left[\mathrm{NTf}_{2}\right]$ were selected in order to evaluate the effect of anion and cation sizes in the bending properties. The microstructure, mechanical and electrical properties of the blend depend on the IL type, which in turn leads to a different bending response. In particular, the mechanical properties are independent on the IL type but the AC conductivity of the composites depend more on the anion type than on the size of the alkyl chain connected to the imidazolium based cation. Thus, the bending response of the IL/PVDF composites is correlated with the anion and cation sizes and a maximum bending response of $0.3 \%$ is achieved for a 10 volts square signal in the IL/PVDF composite with $40 \mathrm{wt} \%$ content of $\left[\mathrm{C}_{2} \operatorname{mim}\right]\left[\mathrm{NTf}_{2}\right]$.
\end{abstract}


Keywords: PVDF, ionic liquid, actuator, electrical conductivity, bending

\section{Introduction}

For the development of micro-electro-mechanical systems (MEMS), artificial muscle, sensor and actuator applications, among others, ionic polymer composites are a type of electroactive polymers (EAPs) particularly interesting due to their lightweight, high flexibility, low operation voltage and biocompatibility, being therefore suitable for implementation in a large variety of areas and devices [1-3]. Among the most promising ionic polymer actuators are the ones based in the introduction of ionic liquids (IL) within the polymer matrix [4]. In those materials, large deformation actuation is achieved at low voltages $(<5 \mathrm{~V})$ based on the diffusion of ions [5]. The actuator device typically consist on the ionic polymer composite and two conductive compliant electrodes deposited on each side of the composite [4].

Further, ionic polymer composites based on IL are interesting for different application areas as they represent suitable electrolytes with negligible vapor pressure, high chemical and thermal stabilities, no volatility, flame retardancy, high ionic conductivity and broad electrochemical potential window [6-9].

Research on ILs/polymer composites for actuators is of increasing interest in order to improve the electrochemical stability window, and the actuation force and frequency at low voltages [10].

Thus, different ILs have been used as dopants for Nafion ionomeric membranes [11], as their integration in self-assembled sulphonated block copolymer electrolytes induce a large strain [12]. These ILs are 1-ethyl-3-methylimidazolium bis(trifluoromethylsulfonyl)imide $\quad\left(\left[\mathrm{C}_{2}\right.\right.$ mim $\left.]\left[\mathrm{NTf}_{2}\right]\right) \quad[13] \quad$ and 1-ethyl-3methylimidazolium tetrafluoroborate $\left(\left[\mathrm{C}_{2} \mathrm{mim}\right]\left[\mathrm{BF}_{4}\right]\right)$ and generated strains from 0.90 to $1.05 \%$ for the frequency range from 0.01 to $0.005 \mathrm{~Hz}$ [14].

Poly(vinylidene fluoride), PVDF [15-17] and its copolymers [13, 18-20], are among the most used polymers for actuators applications, due to their large dielectric constant, high polarity, biocompatibility, easy processing, high piezoelectric coefficients, high mechanical strength and ionic conductivity [21].

Large actuation strains have been observed in poly(vinylidene fluoride-cochlorotrifluoroethylene)/poly(methylmethacrylate), PVDF-CTFE/PMMA with 1-ethyl3-methylimidazolium trifluoromethanesulfonate ([ $\left.\left.\mathrm{C}_{2} \mathrm{mim}\right][\mathrm{TfO}]\right)[18]$; poly(vinylidene 
fluoride-co-hexafluoropropylene), PVDF-HFP with 1-ethyl-3-methylimidazolium tetrafluoroborate $\left(\left[\mathrm{C}_{2} \mathrm{mim}\right]\left[\mathrm{BF}_{4}\right]\right)[19]$ and PVDF-HFP with $\left[\mathrm{C}_{2} \mathrm{mim}\right]\left[\mathrm{BF}_{4}\right]$ with two bucky-gel electrode layers [22]. PVDF-HFP actuators have been also developed with other IL such as $\left[\mathrm{C}_{2} \mathrm{mim}\right]\left[\mathrm{BF}_{4}\right]$ and $\left[\mathrm{C}_{2} \mathrm{mim}\right]\left[\mathrm{NTf}_{2}\right][13]$.

The bending actuation of $\mathrm{PVDF} /\left[\mathrm{C}_{2} \mathrm{mim}\right]\left[\mathrm{NTf}_{2}\right]$ composites has been reported, the actuation strength increasing with increasing IL content and the sample thickness. The maximum bending of $6 \times 10^{-4} \mathrm{~mm}$ was found for a IL content $40 \%$ in weight, an electric voltage of $10.0 \mathrm{~V}$ and a frequency of $0.5 \mathrm{~Hz}$ [16]. The bending actuation for $\mathrm{PVDF} /\left[\mathrm{N}_{1112(\mathrm{OH})}\right]\left[\mathrm{NTf}_{2}\right]$ and $\mathrm{PVDF} /\left[\mathrm{C}_{2} \mathrm{mim}\right]\left[\mathrm{C}_{2} \mathrm{SO}_{4}\right]$ was also demonstrated as a function of voltage for a frequency of $10 \mathrm{mHz}$, the actuation response depending more on IL content than on IL type in this specific case [23].

Taking into account that the 1 - $n$-alkyl-3-methylimidazolium cation $\left[\mathrm{C}_{n} \mathrm{mim}^{+}\right]\left[\mathrm{X}^{-}\right]$is very interesting for IL development based on its conductivity and viscosity, the effect of different IL anions, $\left[\mathrm{NTf}_{2}\right]^{-}$and $[\mathrm{Cl}]^{-}$, as well as cations, $\left[\mathrm{C}_{2} \mathrm{mim}\right]^{+},\left[\mathrm{C}_{6} \mathrm{mim}\right]^{+}$and $\left[\mathrm{C}_{10 \mathrm{mim}}\right]^{+}$, on the physico-chemical properties of IL/PVDF blends has been evaluated as a function of IL weight content [17]. It was demonstrated that IL type strongly influences the physico-chemical characteristics of the composites, allowing to nucleate the electroactive $\beta$-phase of PVDF and therefore to tailor composites for specific applications, such as sensors and actuators [17]. For sensor and actuator application, the $\beta$-phase is the most interesting phase of PVDF due to its piezoelectric coefficient and high dielectric constant [21].

The nucleation of the $\beta$-phase of the polymer is attributed to the interaction between the negative charges of the IL and the positive part of the dipolar moments of the PVDF polymer chains, leading to a preferential all-trans PVDF chain conformation during crystallization [17].

The highest ionic conductivity value with mechanical stability was achieved for IL contents of $40 \mathrm{wt} \%$, being therefore the most suitable concentration for actuator development.

Thus, taking into account the state of the art, it is interesting to perform a suitable correlation between the bending actuation and the IL properties. The main objective of the present work is the evaluation and understanding of the bending actuation in IL/PVDF composites as a function of the alkyl chain length of the cation, $\left[\mathrm{C}_{2} \mathrm{mim}\right]^{+},\left[\mathrm{C}_{6} \mathrm{mim}\right]^{+}$and $\left[\mathrm{C}_{10 \mathrm{mim}}\right]^{+}$, with a size varying from $99.2 \mathrm{~cm}^{3} \mathrm{~mol}^{-1}$ to $236.7 \mathrm{~cm}^{3} \mathrm{~mol}^{-1}$, and of the anion 
([NTf $]^{-}: 158.7 \mathrm{~cm}^{3} \mathrm{~mol}^{-1}$ and $[\mathrm{Cl}]^{-}: 25.9 \mathrm{~cm}^{3} \mathrm{~mol}^{-1}$ ) [24], based on the mechanical and electrical characteristics of those composites.

\section{Experimental details}

\subsection{Materials}

Poly(vinylidene fluoride) (PVDF, Solef 6020) and N,N-dimethylformamide (DMF, 99.5\%) were acquired from Solvay and Merck, respectively. The ionic liquids, 1-ethyl-3methylimidazolium chloride, $\left[\mathrm{C}_{2} \mathrm{mim}\right][\mathrm{Cl}]$, 1-hexyl-3-methylimidazolium chloride, $\left[\mathrm{C}_{6} \operatorname{mim}\right][\mathrm{Cl}]$, 1-decyl-3-methylimidazolium chloride, $\left[\mathrm{C}_{10} \mathrm{mim}\right][\mathrm{Cl}]$, 1-ethyl-3methylimidazolium bis(trifluoromethylsulfonyl)imide, $\left[\mathrm{C}_{2} \operatorname{mim}\right]\left[\mathrm{NTf}_{2}\right]$, 1-hexyl-3methylimidazolium bis(trifluoromethylsulfonyl)imide, [ $\left.\mathrm{C}_{6} \mathrm{mim}\right]\left[\mathrm{NTf}_{2}\right]$ and 1-decyl-3methylimidazolium bis(trifluoromethylsulfonyl)imide, $\left[\mathrm{C}_{10 \mathrm{mim}}\right]\left[\mathrm{NTf}_{2}\right]$ were supplied from Iolitec (Germany) with stated purity of $99 \%$.

\subsection{Composites preparation}

The composites were prepared by the solvent-casting method following the procedure presented in [17]. The polymer PVDF was dissolved in N,N-dimethylformamide (DMF) in a proportion of $15 / 85 \mathrm{wt} \%$ and the corresponding IL was then added to the solution in an IL/polymer weight ratio of $40 \%(\mathrm{w} / \mathrm{w})$. Before this step, $40 \mathrm{wt} \%$ of the IL was added to $6 \mathrm{~mL}$ of $\mathrm{DMF}$ and mixed for $10 \mathrm{~min}$ under mechanical stirring until complete homogenization. After this step, $1 \mathrm{~g}$ of PVDF powder was added to the solution and dissolved under magnetic stirring during $\sim 3 \mathrm{~h}$ at room temperature. Then, the solution was spread on a clean glass substrate at room temperature with a specific thickness and the films were melted in an air oven (Binder, ED23) at a controlled temperature of 210 ${ }^{\circ} \mathrm{C}$ for $10 \mathrm{~min}$. After this period of the time, the casted films were removed from the oven and cooled down to $\sim 23{ }^{\circ} \mathrm{C} \pm 2{ }^{\circ} \mathrm{C}$. Transparent films with final thickness of $45 \pm 5 \mu \mathrm{m}$ were obtained.

\subsection{Composite characterization}

The morphology of the samples was analyzed by scanning electron microscopy (SEM) (Quanta 650 FEG (FEI) Scanning microscope). The samples were coated with gold by magnetron sputtering with a Polaron Coater SC502. 
Dielectric measurements (capacity and dielectric loss) were performed with of a Quadtech 1929 Precision LCR meter at room temperature. The measurements were carried out in the frequency range from $20 \mathrm{~Hz}$ to $1 \mathrm{MHz}$ with an applied voltage of $0.5 \mathrm{~V}$ in samples in the parallel plate condenser geometry in which circular gold electrodes (5 mm diameter) were deposited by magnetron sputtering (Polaron Coater SC502). The a.c. conductivity of the samples was calculated as previously explained in [25] and using equation 1:

$$
\sigma^{\prime}(\omega)=\varepsilon_{0} \omega \varepsilon^{\prime \prime}(\omega)
$$

where $\varepsilon_{0}$ is the permittivity of free space, $\omega=2 \pi f$ is the angular frequency and $\varepsilon^{\prime \prime}(\omega)=\varepsilon^{\prime} \tan \delta$ is the frequency dependent imaginary part of the dielectric permittivity. $\varepsilon^{\prime}$ was calculated from the measurement of the capacity, taking into account the geometrical characteristics of the samples.

The mechanical measurements in the tensile mode were performed at $\sim 23{ }^{\circ} \mathrm{C} \pm 2{ }^{\circ} \mathrm{C}$ with an AG-IS universal testing machine from Shimadzu using a load cell of $50 \mathrm{~N}$ at a stretching rate of $1 \mathrm{~mm} \mathrm{~min}^{-1}$. Rectangular samples with $15 \mathrm{~mm} \times 10 \mathrm{~mm}$ dimension were analyzed. The Young modulus was calculated from linear fits of the stress-strain curves up to $1 \%$ deformation.

Bending measurements were carried out using a high definition Logitech HD 1080p Webcam camera connected to a PC with $200 \mu \mathrm{m}$ accuracy. The samples were prepared with a length of $12 \mathrm{~mm}$ and a width of $2 \mathrm{~mm}$ leaving a free length of $10 \mathrm{~mm}$, after sample attachment in the measurement device. The IL/PVDF actuators consist in three layers: two electrodes and an IL/PVDF film in between.

The actuator was clamped to two needles and connected to an Agilent 33220A function generator [23].

The measurement of the displacement was carried out by applying a square wave signal with voltages from $5 \mathrm{~V}_{\mathrm{pp}}$ to $20 \mathrm{~V}_{\mathrm{pp}}$ at a frequency of $100 \mathrm{mHz}$. This frequency was chosen to allow complete anion and cation migration to the electrodes [26].

The evaluation of the actuation was carried out by analysing the obtained films every 5 seconds, so that a discrete description of the displacement was obtained. Bending $(\varepsilon)$ was quantified by measuring the sample displacement along the $\mathrm{x}$ axes (figure 1), then a relationship between the sample free length (L), thickness (d) and displacement $(\delta)$ was calculated according equation 2 [13]: 


$$
\varepsilon=\frac{2 d \delta}{L^{2}+\delta^{2}}
$$

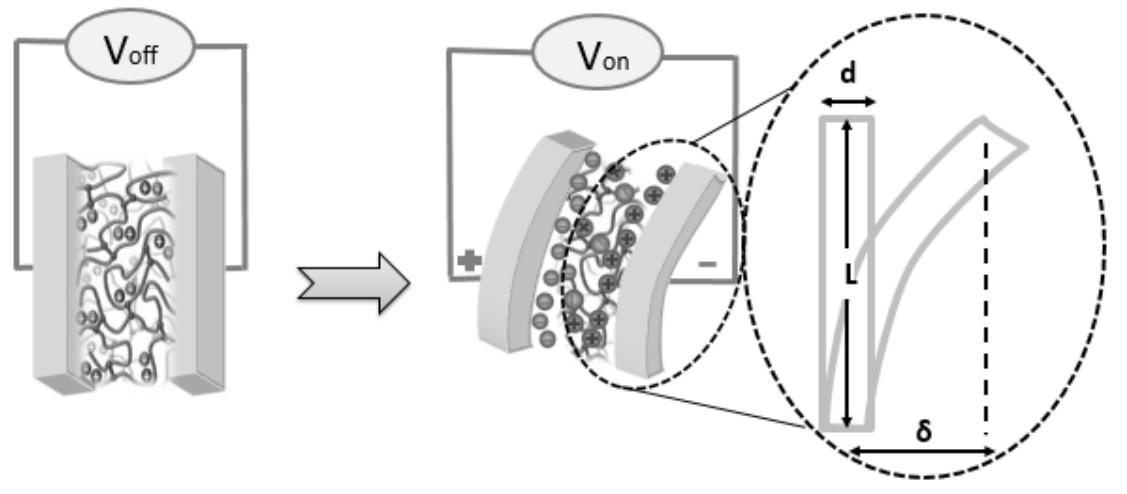

Figure 1 - Schematic representation of the ion migration and bending response of the IL/PVDF composites and definition of the geometrical parameters for the quantitative evaluation of the bending response. 


\section{Results and discussion}

\subsection{Morphology, mechanical and electrical properties}

Representative SEM images of the morphology of the prepared IL/PVDF composites are shown in figure 2 . The microstructure of pristine PVDF (figure $2 \mathrm{a}$ ), $\left[\mathrm{C}_{6} \mathrm{mim}\right][\mathrm{Cl}] / \mathrm{PVDF}$ (figure $2 \mathrm{~b}$ ) and $\left[\mathrm{C}_{6} \mathrm{mim}\right]\left[\mathrm{NTf}_{2}\right] / \mathrm{PVDF}$ (figure $2 \mathrm{c}$ ) samples are shown, as they are representative for the rest of the composites.
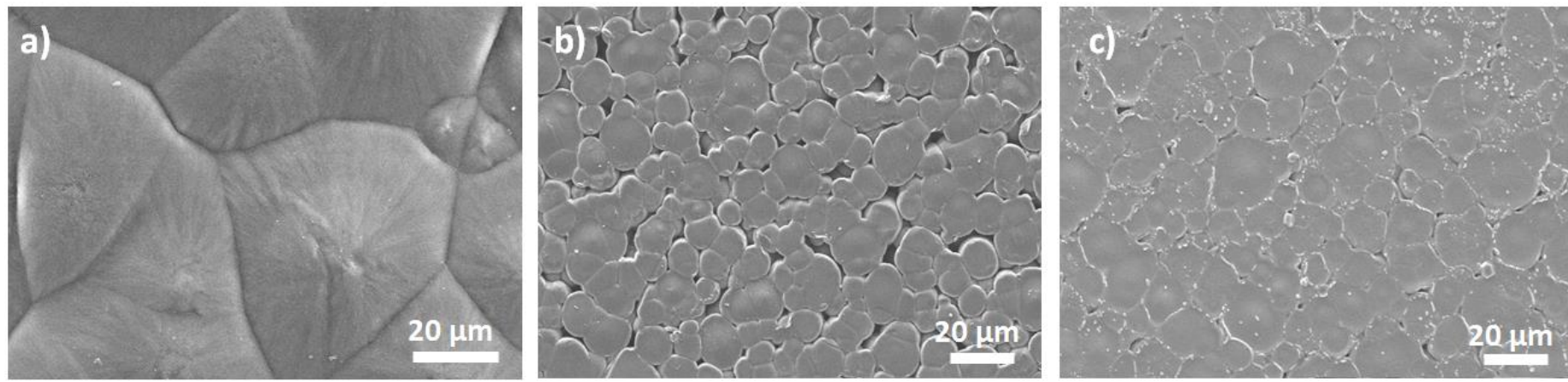

Figure 2 - SEM images of pristine PVDF (a), $\left[\mathrm{C}_{6} \mathrm{mim}\right][\mathrm{Cl}] / \mathrm{PVDF}$ (b) and $\left[\mathrm{C}_{6} \operatorname{mim}\right]\left[\mathrm{NTf}_{2}\right] / \mathrm{PVDF}(\mathrm{c})$ composite samples.

All samples show the spherulitic microstructure characteristic of PVDF, independently of the IL type used for the preparation of the composite. Nevertheless, the IL/PVDF composites (figure $2 b-c$ ) are characterized by a smaller spherulite size than the PVDF sample (Figure 2a): the electrostatic interaction between the IL and the highly polar PVDF polymer chains leads the IL to act not only as nucleation centers for polymer crystallization, but also to modify the crystallization kinetic [17, 27].

The smaller size of the spherulites with the inclusion of the IL within the polymer matrix is independent of the anion and cation type present in the IL. Additionally, the high IL nuclei density hinders the free growth of the spherulites, giving rise to large variation of spherulite sizes [28].

It has been demonstrated [17] that the samples crystallize mainly in the $\beta$-crystalline phase of PVDF independently of the anion and cation types, which is ascribed to the ion- 
dipole interactions [29]. Further, there is a slight decrease of the degree of the crystallinity of the IL/PVDF composites in comparison to pristine PVDF, independently on the IL type [17].

The mechanical properties determined by stress-strain tests indicate a strong decrease of the Young modulus (figure 3a) with the incorporation of the IL, mainly due to the plasticizer effect of the IL [30].
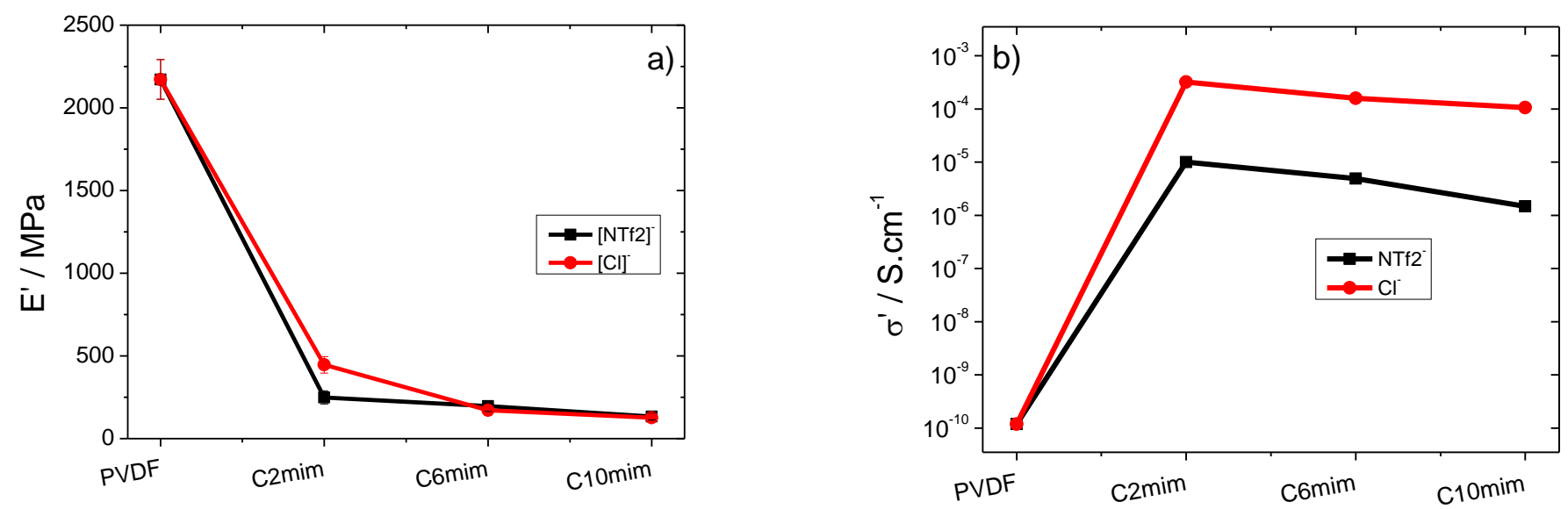

Figure 3 - Young modulus (a) and a.c. electrical conductivity (b) values for the IL/PVDF composites.

The behavior of Young modulus is more dependent on the cation type than on the anion type, decreasing with increasing of the cation chain length $\left(\mathrm{C}_{2} \mathrm{mim}\right.$ to $\left.\mathrm{C}_{10} \mathrm{mim}\right)$. Regarding the anion type, differences are just observed for the shorter cation $\left(\left[\mathrm{C}_{2} \mathrm{mim}^{+}\right]\right)$, being here the decrease of the Young modulus larger for the larger anion, i.e. [NTf $]_{2}$.

The a.c. electrical conductivity strongly increases with the addition of the IL, slightly decreasing with increasing cation chain length. On the other hand, the a.c. electrical conductivity strongly depends on the anion type, being larger for the smaller anion $[\mathrm{Cl}]^{-}$ (figure 3b) [17].

The larger enhancement of the electrical conductivity for the IL/PVDF composites with $[\mathrm{Cl}]^{-}$anion with respect to the ones with $\left[\mathrm{NTf}_{2}\right]^{-}$anion, independently of the cation, is ascribed to the smaller size of the anion and therefore larger mobility, but it can be also due to the contributions of the different water impurity content [31] within the samples. 


\subsection{Bending response}

The bending actuation is caused by the ion movement and re-distribution originated by the application of the external electric field, resulting in their migration and accumulation close to the electrodes. This process depends on the intrinsic characteristics of the IL [32], such as anion and cation size. In fact, the current response appears to be the charging current of an electric double layer (EDL) at the interface between the electrodes and actuators [33]. This actuation is related both to the mechanical and electrical properties of the IL/PVDF composites (figure 1). In the present case, figure $3 \mathrm{a}$ and $\mathrm{b}$ indicate that the electrical properties play a more relevant role in the bending properties as the mechanical characteristics of the IL/PVDF composites are less dependent on the anion and cation present in IL.

Further, once the amount of IL into the polymer matrix is the same (40\% wt), the bending performance will be fully determined by the anion and cation types presents in the IL.

Figure 4 shows the time-displacement response curves for $\left[\mathrm{C}_{6} \mathrm{mim}\right][\mathrm{Cl}]$ (figure $4 \mathrm{a}$ ) and $\left[\mathrm{C}_{6} \operatorname{mim}\right]\left[\mathrm{NTf}_{2}\right]$ (figure $4 \mathrm{~b}$ ) under an applied voltage of 5, 10 and 20 Volts. The behavior observed for these samples are representatives for the other ones.
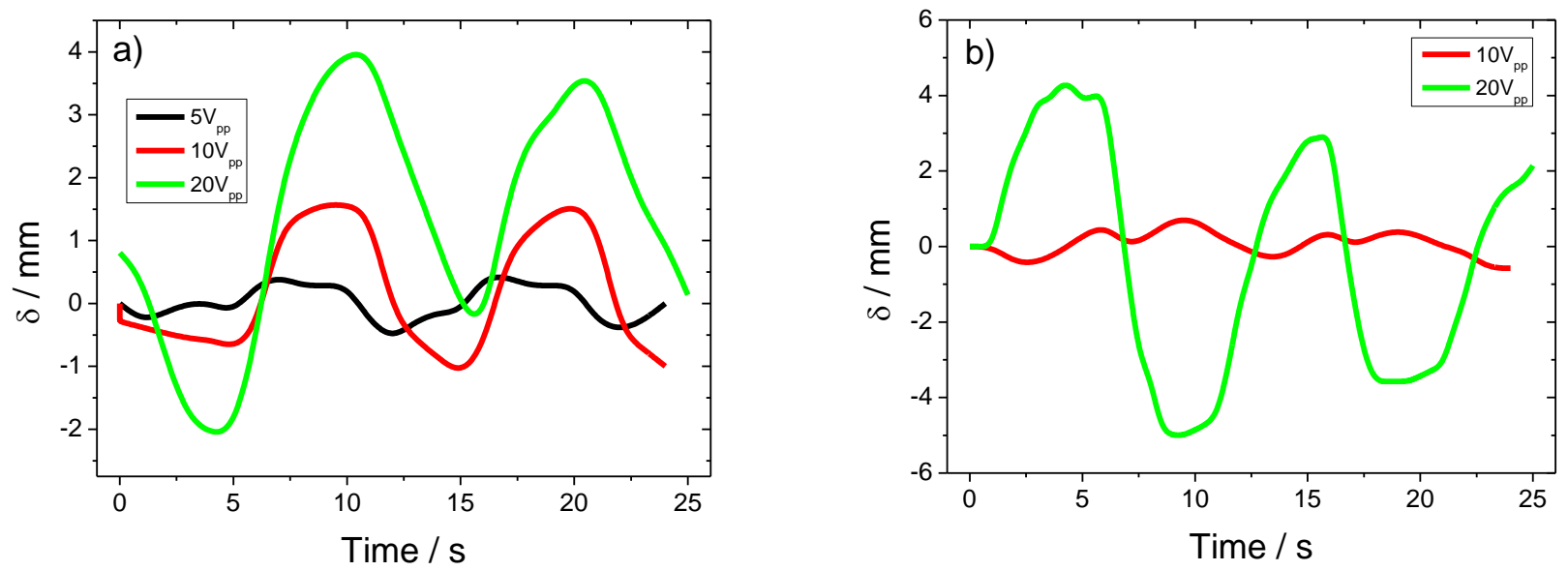

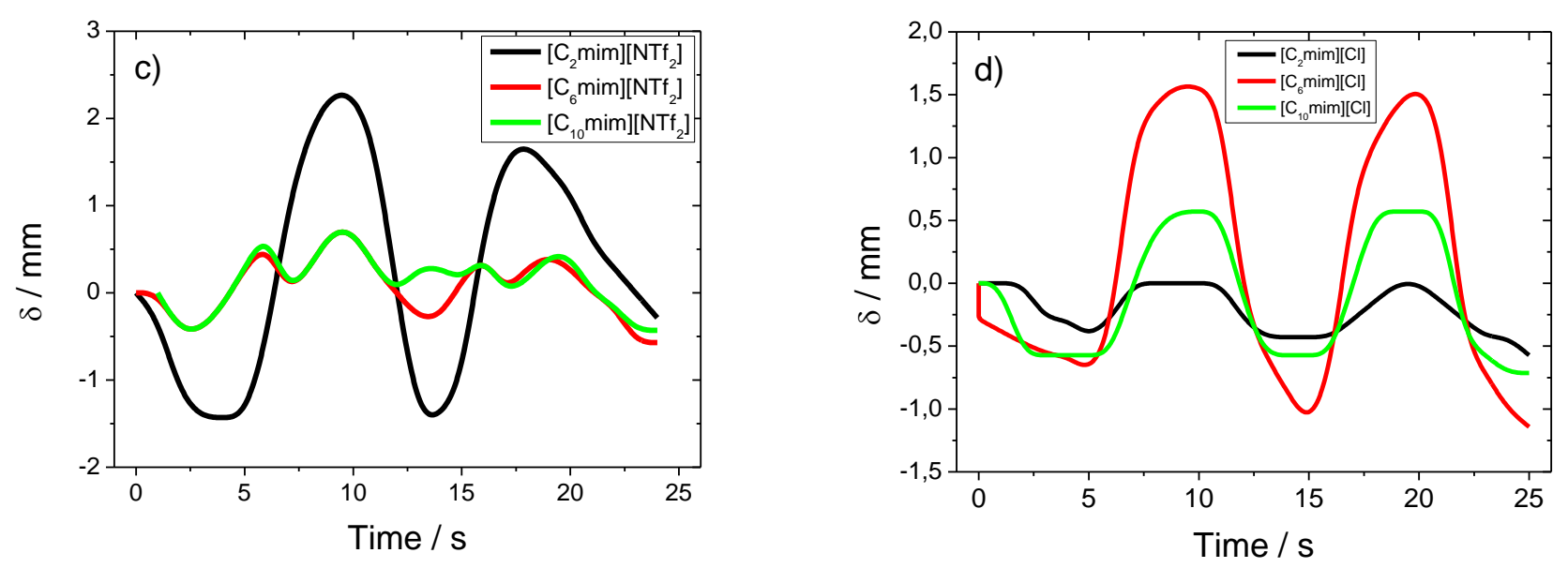

Figure 4 - Displacement of the IL/PVDF composite actuators as a function of time under an applied voltage of 5, 10 and 20 Volts at a frequency of $0.1 \mathrm{~Hz}$ for: a) $\left[\mathrm{C}_{6} \mathrm{mim}\right][\mathrm{Cl}]$ and b) $\left[\mathrm{C}_{6} \mathrm{mim}\right]\left[\mathrm{NTf}_{2}\right]$. Bending response at $0.1 \mathrm{~Hz}$ and $10 \mathrm{Vpp}$ for the PVDF composites containing IL with: c) $\left[\mathrm{NTf}_{2}^{-}\right]$and d) $\left[\mathrm{Cl}^{-}\right]$.

Figure 4a) shows that the displacement increases with increasing applied voltage, which is related to the ion motion within the composite being larger for the larger applied voltage. The bending response also depends on the anion size, an thus, there is no bending response for the samples with $\left[\mathrm{C}_{6} \mathrm{mim}\right]\left[\mathrm{NTf}_{2}\right]$ at $5 \mathrm{~V}_{\mathrm{pp}}$ due to the larger size of the $\left[\mathrm{NTf}_{2}{ }^{-}\right.$ ] anion in comparison with the $\left[\mathrm{Cl}^{-}\right]$, for which a clear bending response is observed.

It is observed that the bending curves are nonperiodic, i.e, not symmetric with respect to the initial position as a function of the applied voltage due of the imbalance of the ion transport, which is related to the different sizes of anion and cation, leading to nonsymmetrical ion dynamic with respect to positive or negative voltages [34]. Further, the bending response is larger for smaller anions $\left(\left[\mathrm{Cl}^{-}\right]\right]$(figure $4 \mathrm{a}$ and $\mathrm{b}$ ) when the same cation is considered $\left(\left[\mathrm{C}_{6} \mathrm{mim}^{+}\right]\right)$.

The effect of different cations was evaluated for two anions, [ $\left.\mathrm{NTf}_{2}^{-}\right]$(figure $4 \mathrm{c}$ ) and $\left[\mathrm{Cl}^{-}\right]$ (figure $4 \mathrm{~d}$ ). For the larger anion, $\left[\mathrm{NTf}_{2}^{-}\right]$, the displacement decreases with increasing cation chain length $\left(\mathrm{C}_{2} \mathrm{mim}\right.$ to $\left.\mathrm{C}_{10} \mathrm{mim}\right)$, as shown in figure $4 \mathrm{c}$. Larger cations lead to hindered dynamics within the polymer matrix and cannot properly react to the applied voltage. In fact, figure $4 c$ shows that the bending is mainly for positive voltages for the two larger cations.

For the $\left[\mathrm{NTf}_{2}{ }^{-}\right]$anion, the best cation is $\left[\mathrm{C}_{2} \mathrm{mim}^{+}\right]$due to its smaller size $\left(99.2 \mathrm{~cm}^{3} \mathrm{~mol}^{-}\right.$ ${ }^{1}$ ), leading to a larger electrical conductivity (figure $3 b$ ). The increase of the alkyl tail size results in the decrease of the diffusion coefficient of the cation and also that of the 
corresponding anion, but to a slightly less extent [35] as is proven by bending results of the figure $4 \mathrm{c}$ )

It is to notice that polymers with defined ionic phases, as it is the case of PVDF, show advantages for improving the bending response by providing organized ion migration along the less tortuous ion-conduction pathways, the combination of the ideal size of anion and cation being crucial for optimized bending actuation [36].

For the IL containing $\left[\mathrm{NTf}_{2}{ }^{-}\right]$anion, the maximum displacement is $3.73 \mathrm{~mm}$ for $\left[\mathrm{C}_{2} \mathrm{mim}^{+}\right]$ and $0.88 \mathrm{~mm}$ for $\left[\mathrm{C}_{10} \mathrm{mim}^{+}\right]$, the bending response calculated after equation 2 being $0.30 \%$ and $0.08 \%$ for $\left[\mathrm{C}_{2} \mathrm{mim}^{+}\right]$and $\left[\mathrm{C}_{10} \mathrm{mim}^{+}\right]$, respectively

One important parameter that affects the electrical conductivity of IL/PVDF composites is the viscosity of the IL and the increment with the alkyl chain length of imidazolium cation is more pronounced in the case of ILs containing the $\left[\mathrm{Cl}^{-}\right]$anion. In the present case for the $\left[\mathrm{Cl}^{-}\right]$anion, the best cation is $\left[\mathrm{C}_{6} \mathrm{mim}^{+}\right]$: the net force of attraction between the cation and anion decreases resulting in the diminution in the ionic character of $\left[\mathrm{C}_{6} \mathrm{mim}\right][\mathrm{Cl}]$, leading to a decrease of the viscosity and an increase of the mobility [37]. In this context, it is observed that for $\left[\mathrm{Cl}^{-}\right]$(figure $4 \mathrm{~d}$ ) the maximum displacement is 2.5 $\mathrm{mm}$ for $\left[\mathrm{C}_{6} \mathrm{mim}^{+}\right]$and the minimum displacement is $0.42 \mathrm{~mm}$ for $\left[\mathrm{C}_{2} \mathrm{mim}^{+}\right]$, leading to a bending of $0.21 \%$ and $0.04 \%$ for $\left[\mathrm{C}_{6} \mathrm{mim}^{+}\right]$and $\left[\mathrm{C}_{2} \mathrm{mim}^{+}\right]$, respectively. Figure $4 \mathrm{~d}$ shows a more symmetric, bidirectional behavior for all samples, migration and accumulation of the ions close to electrodes being similar for positive and negative applied voltages. Thus, the smaller ion and its mobility determine actuator performance more than the size of the alkyl chain length of the cation.

Figure 5 shows a picture of the bending motion of the $\left[\mathrm{C}_{6} \mathrm{mim}\right][\mathrm{Cl}]$ (figure $5 \mathrm{a}$ ) and $\left[\mathrm{C}_{2} \mathrm{mim}\right]\left[\mathrm{NTf}_{2}\right]$ (figure $5 \mathrm{~b}$ ) actuator strip under a \pm 10 and 20 Volts square signal, respectively. The bending motion shown in figure 5 is representative for the other samples. 

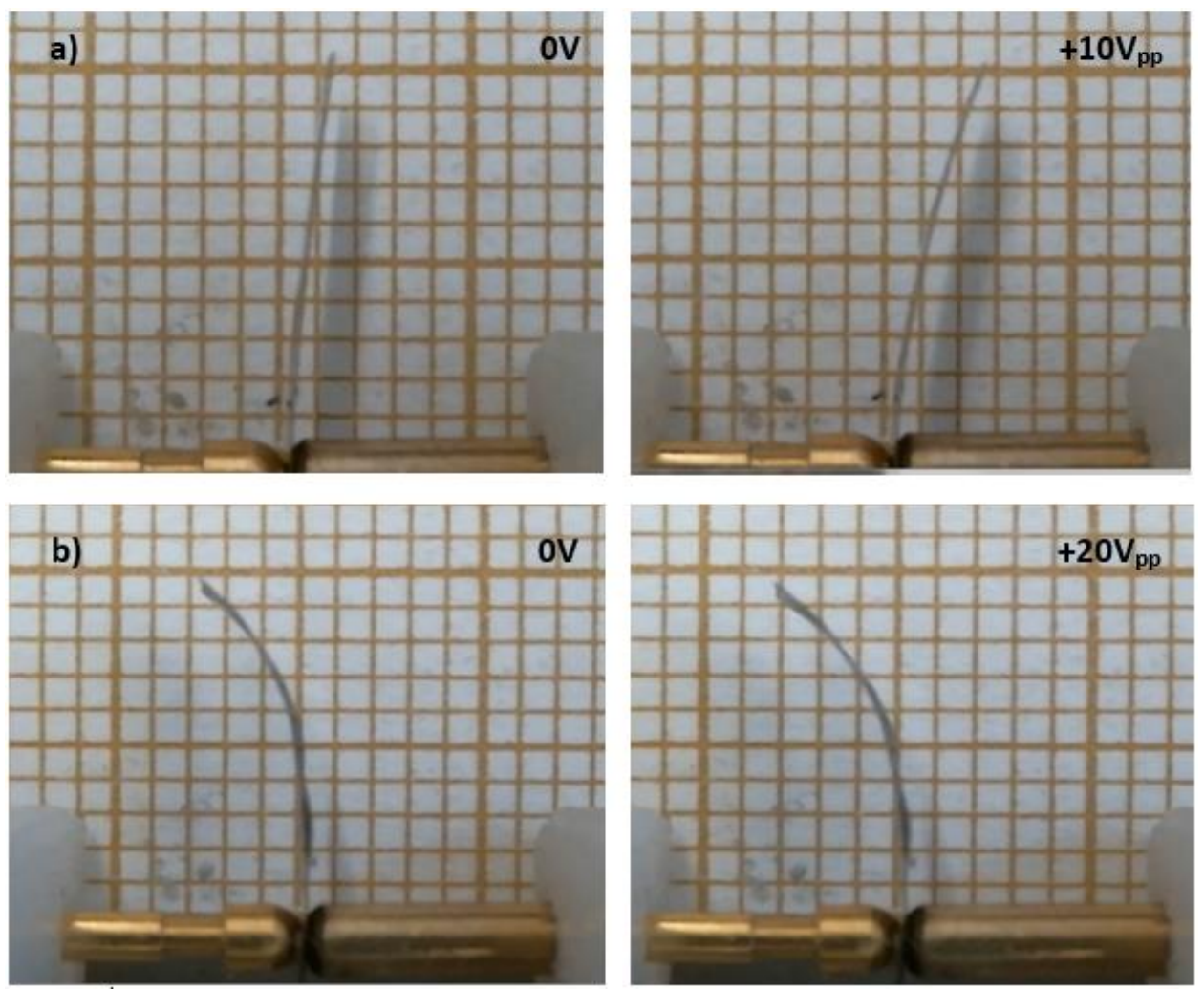

Figure 5 - Picture of the bending motion for: a) $\left[\mathrm{C}_{6} \mathrm{mim}\right][\mathrm{Cl}] / \mathrm{PVDF}$ and $\mathrm{b}$ ) $\left[\mathrm{C}_{2} \mathrm{mim}\right]\left[\mathrm{NTf}_{2}\right] / \mathrm{PVDF}$ under an applied voltage of 10 and 20 Volts square signal, respectively at a frequency of $0.1 \mathrm{~Hz}$.

Thus, the present work demonstrates the role of ionic liquid anion and cation in the bending response of PVDF actuators, the size of both ions being key for obtaining high bending curvature of the actuator. The small size of anion and cation boosts the overall the bending behavior of the actuators. Finally, it is to notice that the best bending response obtained in the present work improves with respect to the ones reported literature $[13,14$, 16].

\section{Conclusion}

IL/PVDF composites based on IL containing different anions and cation with different sizes were prepared by solvent casting for a specific ionic liquid content for bending actuator applications. Independently of the IL type, it is observed that the size of the spherulites decreases with the addition of the IL into the polymer matrix and that IL/PVDF composites shows lower elastic modulus and higher electrical conductivity in comparison to the pristine PVDF matrix. In particular, the a.c. conductivity is more dependent on anion type than on cation size. Finally, the anion and cation size of the IL 
play an important role in the bending of the actuator, a maximum value of $0.3 \%$ bending response being obtained for a IL/PVDF composite with $40 \mathrm{wt} \%$ of $\left[\mathrm{C}_{2} \mathrm{mim}\right]\left[\mathrm{NTf}_{2}\right]$. Thus, the proper selection of IL allows tailoring the materials properties for bending applications.

\section{Acknowledgements}

The authors thank FEDER funds through the COMPETE 2020 Programme and National Funds through FCT - Portuguese Foundation for Science and Technology under Strategic Funding UID/FIS/04650/2013, UID/Multi/04551/2013, UID/QUI/50006/2013, project PTDC/EEI-SII/5582/2014, a contract under Investigador FCT 2012 program (J.M.S.S.E.), and grants SFRH/BD/90215/2012 (JCD) and SFRH/BPD/112547/2015 (CMC). Financial support from the Basque Government Industry Department under the ELKARTEK Program is also acknowledged. The authors (R. M. and S. B. H.) would like to thank the Tunisian Ministry of Higher Education and Research for its financial support. The authors thank the support of M. S. Martins (U. Minho) for supporting the electromechanical measurements.

\section{References}

[1] K.J. Kim, S. Tadokoro, Electroactive polymers for robotic applications artificial muscles and sensors.

[2] Y. Bar-Cohen, Q. Zhang, Electroactive Polymer Actuators and Sensors, MRS Bulletin 33(03) (2008) 173-181.

[3] F. Carpi, E. Smela, Biomedical Applications of Electroactive Polymer Actuators, Wiley2009.

[4] S. Mohsen, J.K. Kwang, Ionic polymer-metal composites: I. Fundamentals, Smart Materials and Structures 10(4) (2001) 819.

[5] K. Asaka, Soft Actuators, Stretchable Electronics, Wiley-VCH Verlag GmbH \& Co. KGaA2012, pp. 305-324.

[6] H. Ohno, Electrochemical aspects of ionic liquids. 2011). 
[7] R. Hagiwara, Y. Ito, Room temperature ionic liquids of alkylimidazolium cations and fluoroanions, Journal of Fluorine Chemistry 105(2) (2000) 221-227.

[8] H. Niedermeyer, J.P. Hallett, I.J. Villar-Garcia, P.A. Hunt, T. Welton, Mixtures of ionic liquids, Chemical Society Reviews 41(23) (2012) 7780-7802.

[9] P.C. Marr, A.C. Marr, Ionic liquid gel materials: applications in green and sustainable chemistry, Green Chemistry 18(1) (2016) 105-128.

[10] K. Onnuri, S. Tae Joo, P. Moon Jeong, Fast low-voltage electroactive actuators using nanostructured polymer electrolytes, Nature Communications 4 (2013).

[11] W. Hong, C. Meis, J.R. Heflin, R. Montazami, Evidence of counterion migration in ionic polymer actuators via investigation of electromechanical performance, Sensors and Actuators, B: Chemical 205 (2014) 371-376.

[12] M.S. Cho, J.D. Nam, H.R. Choi, U.C. Koo, Y. Lee, Preparation of solid polymer actuator based on PEDOT/NBR/ionic liquid, Key Engineering Materials, 2005, pp. 641645.

[13] K. Asaka, K. Mukai, T. Sugino, K. Kiyohara, Ionic electroactive polymer actuators based on nano-carbon electrodes, Polymer International 62(9) (2013) 1263-1270.

[14] N. Terasawa, N. Ono, Y. Hayakawa, K. Mukai, T. Koga, N. Higashi, K. Asaka, Effect of hexafluoropropylene on the performance of poly(vinylidene fluoride) polymer actuators based on single-walled carbon nanotube-ionic liquid gel, Sensors and Actuators, B: Chemical 160(1) (2011) 161-167.

[15] Z. Chen, K.-Y. Kwon, X. Tan, Integrated IPMC/PVDF sensory actuator and its validation in feedback control, Sensors and Actuators A: Physical 144(2) (2008) 231-241. [16] J.C. Dias, A.C. Lopes, B. Magalhães, G. Botelho, M.M. Silva, J.M.S.S. Esperança, S. Lanceros-Mendez, High performance electromechanical actuators based on ionic liquid/poly(vinylidene fluoride), Polymer Testing 48 (2015) 199-205.

[17] R. Mejri, J.C. Dias, A.C. Lopes, S. Bebes Hentati, M.M. Silva, G. Botelho, A. Mão de Ferro, J.M.S.S. Esperança, A. Maceiras, J.M. Laza, J.L. Vilas, L.M. León, S. LancerosMendez, Effect of ionic liquid anion and cation on the physico-chemical properties of poly(vinylidene fluoride)/ionic liquid blends, European Polymer Journal 71 (2015) 304313.

[18] Y. Liu, M. Ghaffari, R. Zhao, J.-H. Lin, M. Lin, Q.M. Zhang, Enhanced Electromechanical Response of Ionic Polymer Actuators by Improving Mechanical Coupling between Ions and Polymer Matrix, Macromolecules 45(12) (2012) 5128-5133. 
[19] K.-S. Kwon, T.N. Ng, Improving electroactive polymer actuator by tuning ionic liquid concentration, Organic Electronics 15(1) (2014) 294-298.

[20] P. Brochu, Q. Pei, Advances in Dielectric Elastomers for Actuators and Artificial Muscles, Macromolecular Rapid Communications 31(1) (2010) 10-36.

[21] P. Martins, A.C. Lopes, S. Lanceros-Mendez, Electroactive phases of poly(vinylidene fluoride): Determination, processing and applications, Progress in Polymer Science 39(4) (2014) 683-706.

[22] K. Mukai, K. Asaka, K. Kiyohara, T. Sugino, I. Takeuchi, T. Fukushima, T. Aida, High performance fully plastic actuator based on ionic-liquid-based bucky gel, Electrochimica Acta 53(17) (2008) 5555-5562.

[23] J.C. Dias, M.S. Martins, S. Ribeiro, M.M. Silva, J.M.S.S. Esperança, C. Ribeiro, G. Botelho, C.M. Costa, S. Lanceros-Mendez, Electromechanical actuators based on poly(vinylidene fluoride) with [N1 $1112(\mathrm{OH})][\mathrm{NTf} 2]$ and [C2mim] [C2SO4], Journal of Materials Science 51(20) (2016) 9490-9503.

[24] A.J.L. Costa, M.R.C. Soromenho, K. Shimizu, I.M. Marrucho, J.M.S.S. Esperança, J.N.C. Lopes, L.P.N. Rebelo, Density, Thermal Expansion and Viscosity of CholiniumDerived Ionic Liquids, ChemPhysChem 13(7) (2012) 1902-1909.

[25] F. Kremer, A. Schönhals, Broadband Dielectric Spectroscopy, Springer Berlin Heidelberg2002.

[26] C. Bonomo, L. Fortuna, P. Giannone, S. Graziani, S. Strazzeri, A nonlinear model for ionic polymer metal composites as actuators, Smart Materials and Structures 16(1) (2007) 1 .

[27] Y. Zhu, C. Li, B. Na, R. Lv, B. Chen, J. Zhu, Polar phase formation and competition in the melt crystallization of poly (vinylidene fluoride) containing an ionic liquid, Materials Chemistry and Physics 144(1-2) (2014) 194-198.

[28] L. He, J. Sun, X. Wang, C. Wang, R. Song, Y. Hao, Facile and effective promotion of $\beta$ crystalline phase in poly(vinylidene fluoride) via the incorporation of imidazolium ionic liquids, Polymer International 62(4) (2013) 638-646.

[29] C. Xing, M. Zhao, L. Zhao, J. You, X. Cao, Y. Li, Ionic liquid modified poly(vinylidene fluoride): crystalline structures, miscibility, and physical properties, Polymer Chemistry 4(24) (2013) 5726-5734.

[30] M. Rahman, H.W. Shoff, C.S. Brazel, Ionic Liquids as Alternative Plasticizers for Poly(vinyl chloride): Flexibility and Stability in Thermal, Leaching, and UV 
Environments, Ionic Liquids in Polymer Systems, American Chemical Society2005, pp. 103-118.

[31] J.A. Widegren, E.M. Saurer, K.N. Marsh, J.W. Magee, Electrolytic conductivity of four imidazolium-based room-temperature ionic liquids and the effect of a water impurity, The Journal of Chemical Thermodynamics 37(6) (2005) 569-575.

[32] D. Wang, R. Montazami, J.R. Heflin, The Effect of Ionic Liquid Uptake and Selfassembled Conductive Network Composite Layers on NafionTM based Ionic Polymer Metal Composite Electromechanical Bending Actuators, MRS Online Proceedings Library Archive 1575 (2013) mrss 13-1575-vv06-03 (6 pages).

[33] S. Imaizumi, Y. Ohtsuki, T. Yasuda, H. Kokubo, M. Watanabe, Printable Polymer Actuators from Ionic Liquid, Soluble Polyimide, and Ubiquitous Carbon Materials, ACS Applied Materials \& Interfaces 5 (13) (2013) 6307-6315.

[34] K. Kruusamäe, A. Punning, A. Aabloo, K. Asaka, Self-Sensing Ionic Polymer Actuators: A Review, Actuators 4(1) (2015) 17.

[35] G.E. Logotheti, J. Ramos, I.G. Economou, Molecular Modeling of ImidazoliumBased [Tf2N-] Ionic Liquids: Microscopic Structure, Thermodynamic and Dynamic Properties, and Segmental Dynamics, The Journal of Physical Chemistry B 113(20) (2009) 7211-7224.

[36] O. Kim, S.Y. Kim, B. Park, W. Hwang, M.J. Park, Factors Affecting Electromechanical Properties of Ionic Polymer Actuators Based on Ionic LiquidContaining Sulfonated Block Copolymers, Macromolecules 47(13) (2014) 4357-4368.

[37] R. Leones, C.M. Costa, A.V. Machado, J.M.S.S. Esperança, M.M. Silva, S. Lanceros-Méndez, Effect of Ionic Liquid Anion Type in the Performance of Solid Polymer Electrolytes Based on Poly(Vinylidene fluoride-trifluoroethylene), Electroanalysis 27(2) (2015) 457-464. 